\title{
Contribution of the D-Serine-dependent pathway to the cellular mechanisms underlying cognitive aging
}

\section{B. Potier', F. R. Turpin ${ }^{1 t}$, P.-M. Sinet', E. Rouaud', J.-P. Mothet ${ }^{2+}$, C. Videau', J. Epelbaum', P. Dutar ${ }^{1}$ and J.-M. Billard ${ }^{1 *}$}

Centre de Psychiatrie et Neurosciences, INSERM, U894, Faculté de Médecine, Université Paris Descartes, Paris, France

2 Laboratoire de Neurobiologie Cellulaire et Moleculaire, CNRS UPR 9040, Gif sur Yvette, France

Edited by:

Thomas C. Foster, University of

Florida, USA

Reviewed by:

Jose M. Delgado-Garcia, University

Pablo de Olavide, Spain

Michael R. Foy, Loyola Marymount

University, USA

Michelle Nicolle, Wake Forest

University School of Medicine, USA

${ }^{*}$ Correspondence:

J.-M. Billard, Centre de Psychiatrie et

Neurosciences, INSERM, U894,

Faculté de Médecine, Université Paris

Descartes, 2 ter rue d'Alésia, 75014

Paris, France. e-mail: jean-marie.

billard@inserm.fr

${ }^{\dagger}$ Present address:

F. R. Turpin and J.-P. Mothet, INSERM U862, Neurocentre Magendie, 146 rue Léo Saignat, Bordeaux 33077, France.
An association between age-related memory impairments and changes in functional plasticity in the aging brain has been under intense study within the last decade. In this article, we show that an impaired activation of the strychnine-insensitive glycine site of $\mathrm{N}$-methyl-D-aspartate receptors (NMDA-R) by its agonist D-serine contributes to deficits of synaptic plasticity in the hippocampus of memory-impaired aged rats. Supplementation with exogenous D-serine prevents the age-related deficits of isolated NMDA-R-dependent synaptic potentials as well as those of theta-burst-induced long-term potentiation and synaptic depotentiation. Endogenous levels of D-serine are reduced in the hippocampus with aging, that correlates with a weaker expression of serine racemase synthesizing the amino acid. On the contrary, the affinity of D-serine binding to NMDA-R is not affected by aging. These results point to a critical role for the D-serine-dependent pathway in the functional alterations of the brain underlying memory impairment and provide key information in the search for new therapeutic strategies for the treatment of memory deficits in the elderly.

Keywords: memory, serine racemase, NMDA receptors, hippocampus, synaptic plasticity

\section{INTRODUCTION}

In the general decline that gradually develops with age, learning and memory deficits are frequent features. Studies in animal models of aging have confirmed the occurrence of cognitive decline with age and shown that it concerns several forms of memory, including spatial, associative and long-term memory (Winocur and Moscovitch, 1990; Gallagher and Rapp, 1997; Miyamoto, 1997; Houston etal., 1999; Norris and Foster, 1999; Clayton et al., 2002a; Sykova et al., 2002; Rosenzweig and Barnes, 2003; Gruart et al., 2008). These studies emphasize the role of the hippocampus and related structures in age-related memory deficits, demonstrating that the functional properties of hippocampal networks are particularly vulnerable to aging (Landfield, 1988; Foster and Norris, 1997; Thibault et al., 2007). In particular, the study of long-lasting modifications of glutamatergic neurotransmission such as long-term potentiation (LTP), long-term depression and LTP reversal (depotentiation), now considered to be the functional substrates of memory encoding (Izquierdo and Medina, 1995; Kim and Linden, 2007), have demonstrated changes in the threshold and/ or magnitude of synaptic plasticity with age (Foster, 1999; Barnes, 2003). Although several mechanisms may account for these changes (Rosenzweig and Barnes, 2003; Foster, 2007), most of these studies have focused on the activation of the $N$-methyl-D-aspartate subtype of glutamate receptors ( $\mathrm{N}$-methyl-D-aspartate receptors, NMDA$\mathrm{R})$. Indeed, these receptors play a major role in regulating synaptic strength, by means of their high permeability to $\mathrm{Ca}^{2+}$, which triggers the activation of specific protein kinases and phosphatases (Wang et al., 1997). Although evidence indicates that NMDA-R activation is impaired in aged rodents (Barnes et al., 1997; Potier et al., 2000), the mechanisms that significantly contribute to this alteration have yet to be definitely identified and it remains to be determined whether it is really involved in age-related deficits in synaptic plasticity.

In addition to glutamate, NMDA-R activation requires the binding of a co-agonist at the strychnine-insensitive glycine site (Johnson and Ascher, 1990). Recent developments indicate that the amino acid D-serine, rather than glycine itself, is the main endogenous co-agonist of NMDA-R in cerebral areas involved in memory processes, and in the hippocampus in particular (Mothet et al., 2000). Moreover, it has been shown that the induction of LTP both in hippocampal cultures and in slice preparations is blocked when D-serine is absent from the extracellular space (Yang et al., 2003; Mothet et al., 2006). These results suggest a possible contribution of D-serine to the impairment of NMDA-R activation and functional plasticity that takes place in the aging brain, and consequently a role for the amino acid in age-related memory defects.

In this report, we present our recent experimental results indicating that the manipulation of $\mathrm{D}$-serine levels at the synapse may be an alternative strategy for the development of new treatments for cognitive aging.

\section{MATERIALS AND METHODS ANIMAL PROTOCOLS}

All animal experiments were performed in strict compliance with the European Communities Council Directive (86/809/EEC) regarding the care and use of animals for experimental procedures and 
approved by the local ethics committee. Experiments were conducted on "adult" (3-6 months old, $n=58$ ) and "aged" (25-33 months old, $n=57)$ male Sprague-Dawley rats purchased from IFFA-CREDO (France). Rats were maintained on a $12 \mathrm{~h}$ controlled light-dark cycle at a constant temperature $\left(22 \pm 2^{\circ} \mathrm{C}\right)$ with ad libitum access to food and water.

\section{BEHAVIORAL TESTS}

The task was a modified version of the Morris water maze (Morris et al., 1982). Each rat was first trained to swim to a visible platform $(13 \mathrm{~cm} \times 13 \mathrm{~cm})$ placed in a fixed position in one of the quadrants of a circular pool ( $150 \mathrm{~cm}$ in diameter), painted black and filled with water at $21-22^{\circ} \mathrm{C}$. The platform was $2 \mathrm{~cm}$ above the surface of the water, and could easily be seen by the rats. The time (escape latency) and distance swum before finding the platform were then determined. If the rat did not find the platform within $60 \mathrm{~s}$, it was placed on the platform and left for $35 \mathrm{~s}$. Four trials per day were carried out for 6 days. A different (randomly determined) starting location was used for each trial. Visual cues were present around the pool.

During the second phase of testing (place version), the rat was trained to swim to an invisible platform that was located at a position different from that used during the visible platform trial. The platform was located $2 \mathrm{~cm}$ below the surface of the water. Four trials per day were carried out for 6 days. The position of the platform remained the same for the 6 days of the test. For each trial, the time and distance to platform and swim speed were measured using Smart $_{C}$ software. On day 7 (probe trial), the hidden platform was removed and the time spent by the rat swimming through the different quadrants, including the quadrant in which the platform was situated during place learning, was registered over a $90-$ s period.

\section{ELECTROPHYSIOLOGY}

Transverse hippocampal slices $(400 \mu \mathrm{m})$ were obtained from rats anesthetized with halothane before decapitation. Slices were prepared in ice-cold artificial cerebrospinal fluid (aCSF) and placed in a holding chamber for at least $1 \mathrm{~h}$. The composition of aCSF was (in mM): $\mathrm{NaCl} 124, \mathrm{KCl} 3.5, \mathrm{MgSO}_{4} 1.5, \mathrm{CaCl}_{2} 2.3, \mathrm{NaHCO}_{3} 26.2$, $\mathrm{NaH}_{2} \mathrm{PO}_{4} 1.2$, and glucose 11. A single slice at a time was transferred to the recording chamber and continuously superfused with aCSF pre-gassed with $95 \% \mathrm{O}_{2} / 5 \% \mathrm{CO}_{2}$.

Extracellular field excitatory postsynaptic potentials (fEPSPs) were obtained at room temperature from the apical dendritic layer of the CA1 area after electrical stimulation (100 $\mu$ s duration) of Schaffer collaterals and commissural fibers. Input/Output (I/O) curves of NMDA-R-mediated synaptic responses were plotted for adult and aged rats from slices superfused for $40 \mathrm{~min}$ in low $\mathrm{Mg}^{2+}$ aCSF supplemented with the $\alpha$-amino-3-hydroxy-5-methyl-4isoxazolepropionic acid (AMPA)/kainate receptor antagonist 2,3dioxo-6-nitro-1,2,3,4-tetrahydrobenzoquinoxaline-7-sulfonamide (NBQX, $10 \mu \mathrm{M})$. A knife cut was introduced to separate CA3 and CA1 in order to prevent the propagation of epileptiform discharges. The slope of three averaged fEPSPs was measured and plotted against different intensities of stimulation (from 0 to $500 \mu \mathrm{A}$ ) using Acquis 1 software (CNRS, Paris, France).

For experiments investigating LTP, two different conditioning stimuli were delivered after a baseline acquisition of $15 \mathrm{~min}$. In the case of high frequency stimulation (HFS), the stimulus consisted of two trains $(100 \mathrm{~Hz}$ for $1 \mathrm{~s}$ ) separated by a 20 -s interval. In the case of theta-burst stimulation (TBS), it consisted of five trains of four pulses at $100 \mathrm{~Hz}$ separated by $200 \mathrm{~ms}$. This sequence was repeated three times with an interval of $10 \mathrm{~s}$. In both HFS and TBS experiments, testing with a single pulse was then resumed for $60 \mathrm{~min}$ to determine the level of stable LTP.

In order to investigate the depotentiation of synaptic transmission, a low frequency conditioning stimulus (LFS, 900 pulses, $1 \mathrm{~Hz}$ ) was applied $1 \mathrm{~h}$ after HFS delivery. Tests with a single pulse were resumed for at least $40 \mathrm{~min}$ after LFS. To study the effects of exogenous D-serine, the co-agonist was applied throughout the recording except for the depotentiation paradigm where it was applied 50 min after HFS delivery, once LTP was stabilized. The co-agonist was then maintained until the end of the recording.

\section{AUTORADIOGRAPHY}

$\left[{ }^{3} \mathrm{H}\right] \mathrm{L}-689.560(22.41 \mathrm{Ci} / \mathrm{mmol}$ or $0.83 \mathrm{TBq} / \mathrm{mmol})$ was obtained from Tocris Cookson, Bristol (UK). The brain of adult and aged rats were quickly removed, frozen for $30 \mathrm{~s}$ in isopentane at $-40^{\circ} \mathrm{C}$ and stored at $-80^{\circ} \mathrm{C}$. Coronal sections $(14 \mu \mathrm{m})$ were cut on a cryostat at $-15^{\circ} \mathrm{C}$ and mounted onto glass slides. Brain sections were preincubated with $50 \mathrm{mM}$ Tris acetate buffer $(\mathrm{pH} \mathrm{7.0)}$ at room temperature for $30 \mathrm{~min}$ to remove endogenous free D-serine. For competition studies, sections were incubated with Tris acetate buffer supplemented with $10 \mu \mathrm{M}$ strychnine and $1 \mathrm{nM}\left[{ }^{3} \mathrm{H}\right] \mathrm{L}-689.560$ containing D-serine, glycine and L-689.560 at $4^{\circ} \mathrm{C}$ for $120 \mathrm{~min}$. After incubation, the slides were rinsed four times with cold Tris acetate buffer $\left(4^{\circ} \mathrm{C}\right)$ for a total of $20 \mathrm{~s}$ and then in distilled water at the same temperature for $5 \mathrm{~s}$. After drying, slides were placed on $\left[{ }^{3} \mathrm{H}\right]$-sensitive film (Hyperfilm- ${ }^{3} \mathrm{H}$, Amersham) for two months at $4^{\circ} \mathrm{C}$. The film was developed with Dektol (Kodak) for $2 \mathrm{~min}$ and analyzed using an X-ray film digitizer, RAG500, and Biocom software (Les Ulis, France).

\section{DETERMINATION OF D-SERINE CONTENT IN HIPPOCAMPAL SLICES}

Free amino acids were extracted from pooled brain slices with trichloroacetic acid and stored at $-80^{\circ} \mathrm{C}$ until assay. Two different procedures were used to determine $\mathrm{D}$-serine content. The first technique quantified $\mathrm{D}$-serine using a chemiluminescent assay based on the DAAO/HRP/luminol system (Wolosker et al., 1999). In the second approach, high-performance liquid chromatography (HPLC) analysis was performed using pre-column derivatization of samples with $\mathrm{O}$-phthaldialdehyde and $\mathrm{N}$-acetyl cysteine. Dia-stereo-isomers were resolved in the isocratic phase on a C18 Nova Pak column. In both procedures, the amount of $\mathrm{D}$-serine was adjusted to protein content as determined by a Bio-Rad DC protein assay (Bio-Rad Laboratories, Hercules, CA, USA). Standards of D-serine were used to normalize the results.

\section{SEMI-OUANTITATIVE IMMUNOBLOT ANALYSIS}

Western blot analysis was performed as described previously (Puyal et al., 2002). Briefly, after lysis, protein extracts were subjected to electrophoresis (12\% SDS-polyacrylamide gel) and electroblotted onto PVDF membranes (Immobilon-P, Millipore). Membranes were probed with a polyclonal antibody to DAAO (1:2000, Nordic Immunological Laboratories, Tilburg, The Netherlands), a polyclonal antibody to serine racemase (1:200, Santa Cruz Biotechnology, 
Wiltshire, UK) or a monoclonal $\alpha$-Tubulin antibody (1:400, Santa Cruz Biotechnology) for $1 \mathrm{~h}$ at room temperature. After washing, they were incubated with peroxidase-conjugated anti-rabbit, anti-goat and anti-mouse immunoglobulin $\mathrm{G}$ respectively (IgG; 1:2000, Vector Laboratories Burlingame, USA). Immunoblots were developed using enhanced chemiluminescence (ECL; Amersham Biosciences, Little Chalfont Buckinghamshire, UK). Molecular sizes were estimated by separating prestained molecular weight markers $(6.5-175 \mathrm{kDa})$ in parallel (New England BioLabs, Hertfordshire, UK). Protein bands of interest were analyzed by measuring optical density using scanning densitometry. Densitometric results for serine racemase and DAAO were normalized to the density of $\alpha$ Tubulin. Each blot included three successive dilutions of samples for the quantification of variations in density.

\section{QUANTITATIVE REAL-TIME POLYMERASE CHAIN REACTION (RT-PCR)}

Total RNA was prepared from frozen tissues using the RNeasy Midi kit (Qiagen). Total RNA was converted to cDNA using M-MLV reverse transcriptase and random hexanucleotide primers designed using PrimerExpress (Applied Biosystems), as follows. Serine racemase: (sense: 5'-GATTCGAGGTGCCCTTAACG-3'; antisense: 5'-TTGGGCTTCCCTT CTAAAGTATCA-3'), D-amino acid oxidase (sense: 5'-CCTCAGGTCCG GCTAGAAAGA-3'; antisense: 5'-GGATGACCTCTGCACTTGAAGAT-3'), glial fibrillary acidic protein (GFAP) (sense: $5^{\prime}$-TGACCGCTTTGCTAGCTACATC3'; antisense: 5'-GCGCCTTGTT TTGCTGTTC-3') and MAP2 (sense: $5^{\prime}$-AGATCAGAAAGACTGGTTCATCGA-3'; antisense: 5' CAGCTAAACCCCATTCATCCTT-3'). PCR reactions $(20 \mu$ l total volume) were performed with Sybr Green PCR master mix using standard protocols on an ABI 7000 Sequence Detection System. Raw Ct values were obtained with SDS 2.0 and were used for relative expression calculations.

\section{DRUGS}

All drugs were applied in aCSF and included NBQX $(10 \mu \mathrm{M}$ in DMSO), D-2-amino-5-phosphonovalerate (D-APV, 30-80 $\mu \mathrm{M}$ ), D-serine $(2-200 \mu \mathrm{M})$, L-serine $(100 \mu \mathrm{M}), \operatorname{L689.560}(10 \mu \mathrm{M})$ and nifedipine $(50 \mu \mathrm{M})$. Drugs were purchased from Tocris (Illkirch, France).

\section{STATISTICS}

All results are expressed as means \pm SEM. Behavioral results and time-course of synaptic plasticity were analyzed by one or two-ways analyses of variance (ANOVA) with repeated measures, followed by post hoc multiple comparisons tests (Fisher's PLSD) (Statview ${ }^{\varpi}$ ). The sensitivity of NMDA-R-mediated fEPSPs to exogenous D-serine was determined using Student's paired $t$-test while the effects of age on other parameters (magnitude of LTP over the last 15 min of recordings, expression of proteins involved in the $\mathrm{D}$-serine pathway, $\mathrm{D}$-serine levels) were analyzed using an unpaired $t$-test. In all cases, differences were considered significant when $p \leq 0.05$.

\section{RESULTS}

Spatial learning was explored in adults $(n=10)$ and aged animals $(n=12)$ using different versions of the Morris water maze protocol. As illustrated in Figure 1A (left), the distance swum to find the platform differed greatly between groups $(p<0.0001)$ and a significant interaction between group and time was observed, since aged rats swam longer distances before reaching the hidden platform in the "place" version of the task (interaction of distance $\times$ group/age, $p<0.01)$. When each group was examined separately, adult rats efficiently learned the position of the platform across trials, as demonstrated by a significant decrease in the distance swum before finding the platform in each subsequent trial $(p<0.005)$, whereas aged rats did $\operatorname{not}(p=0.3)$. When animals were tested $24 \mathrm{~h}$ after the end of the learning sessions, adult rats spent more time swimming in the quadrant in which the platform was located during place learning, whereas aged ones did not (Figure 1A, right). In contrast, the two groups of animals did not differ in swim speed during place learning $(15.3 \pm 0.9 \mathrm{~cm} / \mathrm{s}$ in adults vs. $12.4 \pm 1.1 \mathrm{~cm} / \mathrm{s}$ in aged animals) and in distance swum or time to escape onto a visible platform in the cued version of the maze (not shown). These results indicate that aged rats are significantly impaired with respect to spatial learning and that these deficits are independent of sensory and/or motor dysfunctions.

\section{AGE-RELATED CHANGES IN SYNAPTIC PLASTICITY}

Since spatial learning has been associated with the capacity of hippocampal neuronal networks to adapt synaptic strength to ongoing changes in presynaptic activity (Izquierdo and Medina, 1995; Lynch, 2004; Kim and Linden, 2007), we compared the induction and expression of synaptic plasticity in hippocampal slices from adults and aged rats, including high-frequency (HFS) and thetaburst (TBS)-patterns to study LTP, and HFS followed $1 \mathrm{~h}$ later by low frequency stimulation (LFS) to evaluate depotentiation (see Materials and Methods).

Following the HFS protocol, recordings in slices from adult rats $(n=20)$ showed a long-term increase in synaptic transmission (Figure 1B, left) of $48.7 \pm 5.4 \%$, averaged from the last $15 \mathrm{~min}$ of recordings (Figure 1B, right). LTP generated in slices from aged rats $(n=13)$ had a magnitude $(50.4 \pm 8.7 \%)$ similar to that recorded in adults (Figure 1B, right). However, it is worth noting that the fEPSPs amplitude rapidly returned to baseline levels in slices from adult rats $(n=10)$ when HFS was delivered in the presence of the NMDA-R antagonist D-APV $(80 \mu \mathrm{M})$, whereas a long lasting potentiation still remained under the same conditions in slices from aged animals $(17.1 \pm 4.9 \%, n=10$ when averaged from the last 15 min of recordings). HFS-induced LTP was prevented in aged rats only when the conditioning stimulus was delivered in the presence of D-APV and of the voltage-gated calcium channel (VGCC) blocker nifedipine $(50 \mu \mathrm{M})$ (Figure S1 in Supplementary Material).

Under control conditions, a low frequency stimulus $(1 \mathrm{~Hz}$, $15 \mathrm{~min}$ ) delivered $1 \mathrm{~h}$ after HFS induced an LTP reversal or depotentiation in slices from adult animals $(n=9)$ but had little effect on slices from aged rats $(n=19)$ (Figure 1C, left). Indeed, the percent reversal calculated from the last $15 \mathrm{~min}$ of recordings averaged $32.3 \pm 2.7 \%$ in the former and only $10.7 \pm 2.3 \%$ in the latter, indicating that LTP reversal was affected by age (Figure 1C, right).

In the theta-burst paradigm of stimulation (TBS), synaptic transmission was potentiated in slices from adult rats $(n=12)$ (Figure 1D, left), resulting in a $35.4 \pm 2.4 \%$ increase in amplitude. TBS-induced LTP was also recorded in slices from old animals $(n=13)$ (Figure 1D, left) but the percent increase $(19.4 \pm 4.7 \%)$ was significantly lower than that reached in adult rats $(p=0.02)$ (Figure 1D, right). Contrary to our results with HFS-induced LTP, the long-lasting increase in 
A
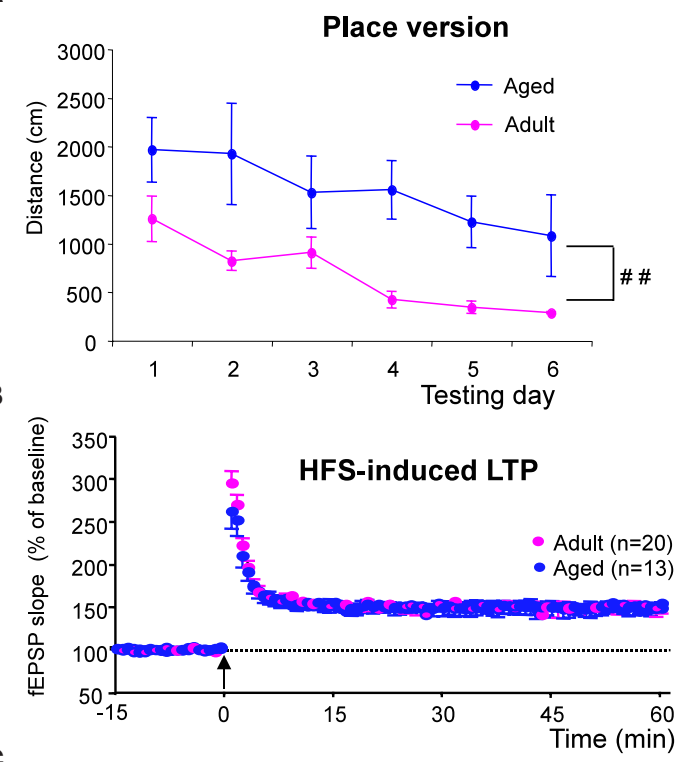

C

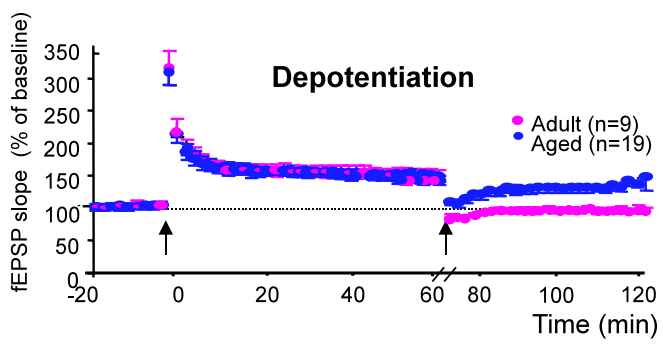

D

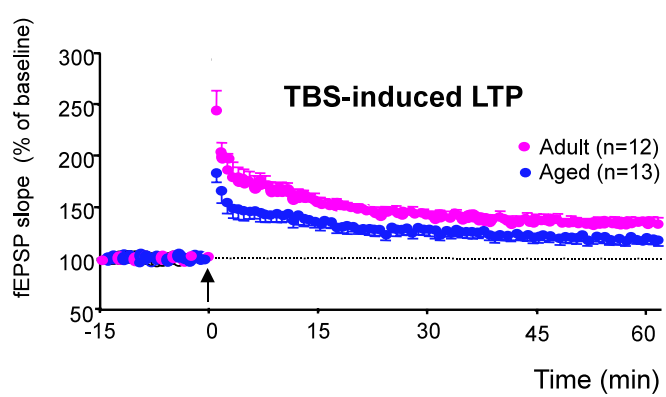

Probe trial
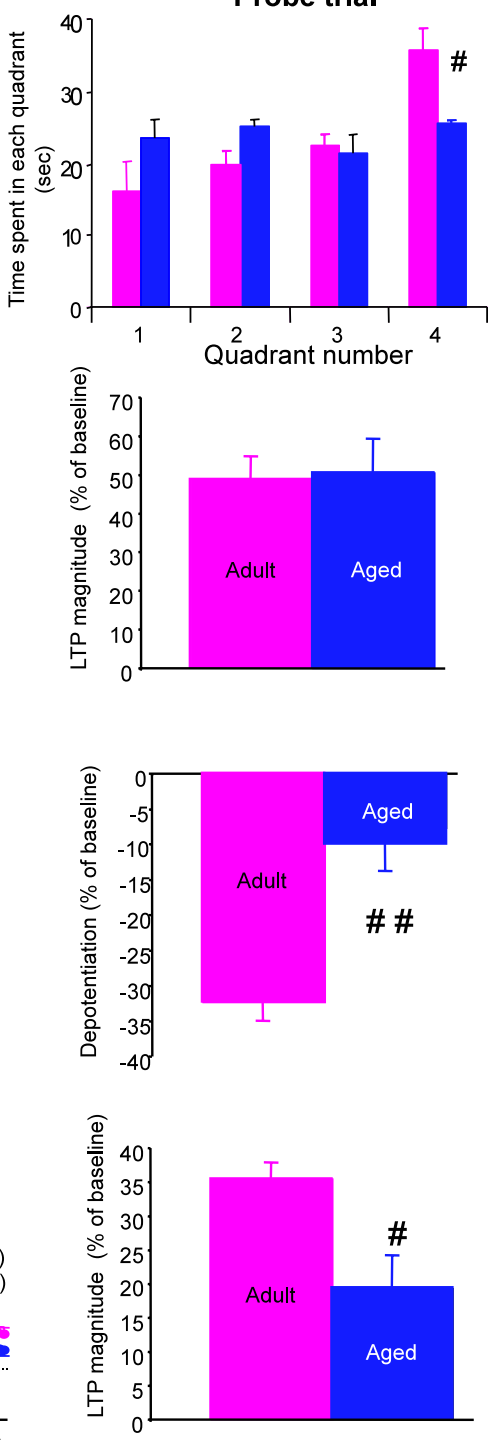

FIGURE 1 | Spatial learning and hippocampal synaptic plasticity are impaired in aged rats. (A, left) Comparison of the distance swum before escaping onto the hidden platform over 6 days of training in adult and aged rats (\#\#p<0.01, repeated measures ANOVA). (A, right) Comparison of time spent by rats swimming through the different quadrants, including quadrant 4, where the platform was situated during place learning, registered over a 90-s probe trial $(\# p<0.05$, unpaired $t$-test). (B, left) Time-course of LTP induction in adult and aged rats by HFS (arrow). (B, right) Comparison of mean LTP magnitude ( \pm SEM) calculated for the last 15 min of recording. (C, left) Time course of depotentiation of previously HFS-potentiated synaptic responses induced in adult and aged rats by LFS. (C, right) Comparison of depotentiation magnitude ( \pm SEM) calculated for the last $15 \mathrm{~min}$ of recording.

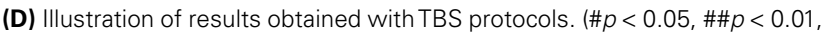
unpaired $t$-test). synaptic transmission induced by TBS was totally blocked both in adult $(n=6)$ and aged rats $(n=7)$ when the conditioning stimulus was delivered in the presence of D-APV $(80 \mu \mathrm{M})$.

\section{AGE-RELATED CHANGES IN ISOLATED NMDA-R-MEDIATED SYNAPTIC RESPONSES: EFFECTS OF D-SERINE}

Except for the HFS-induced LTP in aged rats in which VGCC were also concerned, the specific antagonist D-APV alone was able to prevent the expression of synaptic plasticity in both groups of animals, confirming the pivotal role of NMDA-R in this process. We therefore subsequently looked for changes in the behavior of isolated NMDA-R-mediated synaptic potentials that could account for these age-related changes in synaptic plasticity.

Synaptic potentials were recorded in low- $\mathrm{Mg}^{2+}$ medium supplemented with the AMPA receptor antagonist NBQX $(10 \mu \mathrm{M})$, and were blocked by D-APV $(30 \mu \mathrm{M})$ added at the end of the recordings (Figure 2A). I/O curves plotted for data collected using 53 slices from 24 adult rats and 37 slices from 19 aged 


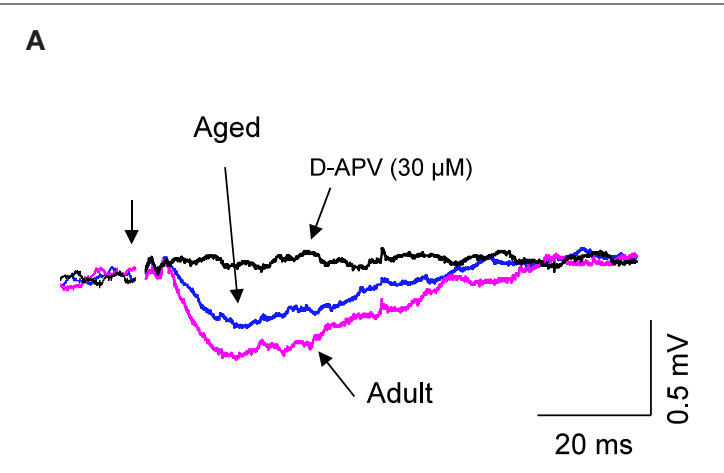

C

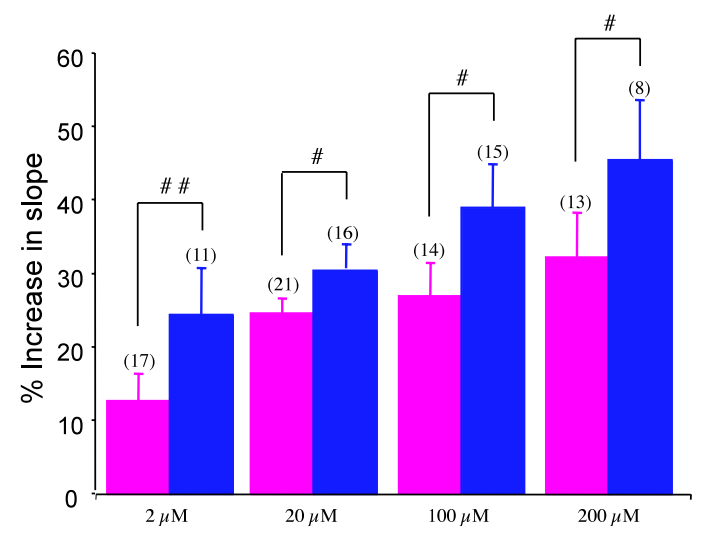

FIGURE 2 | D-Serine prevents age-related deficits in isolated NMDA-R synaptic potentials. (A) Representative NMDA-R-mediated synaptic potential induced by the stimulation of glutamatergic afferents (first arrow) and recorded in an adult (pink trace) and in an aged (blue trace) rat for a stimulus intensity of $400 \mu \mathrm{A}$, and the loss of the synaptic response in the presence of D-APV $(30 \mu \mathrm{M})$ (black trace). (B) Plot of the mean NMDA-R-mediated fEPSP slope ( \pm SEM) against
B

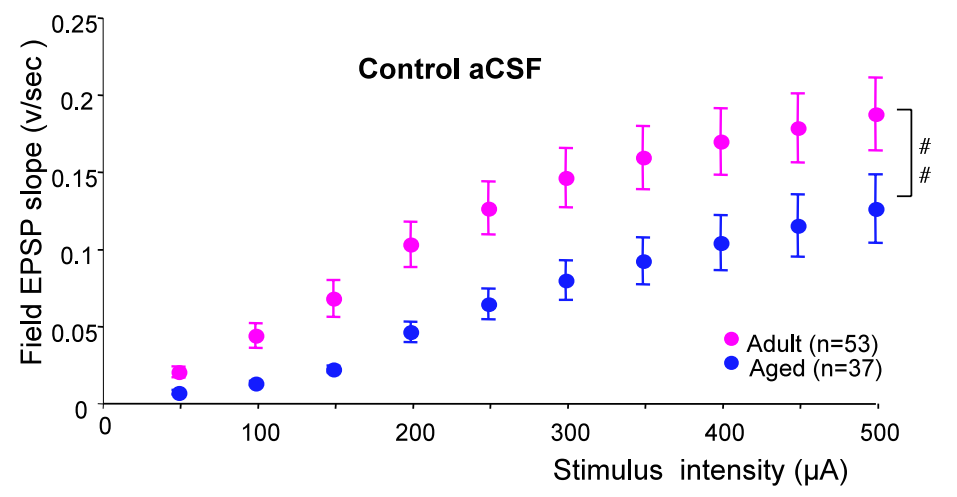

D

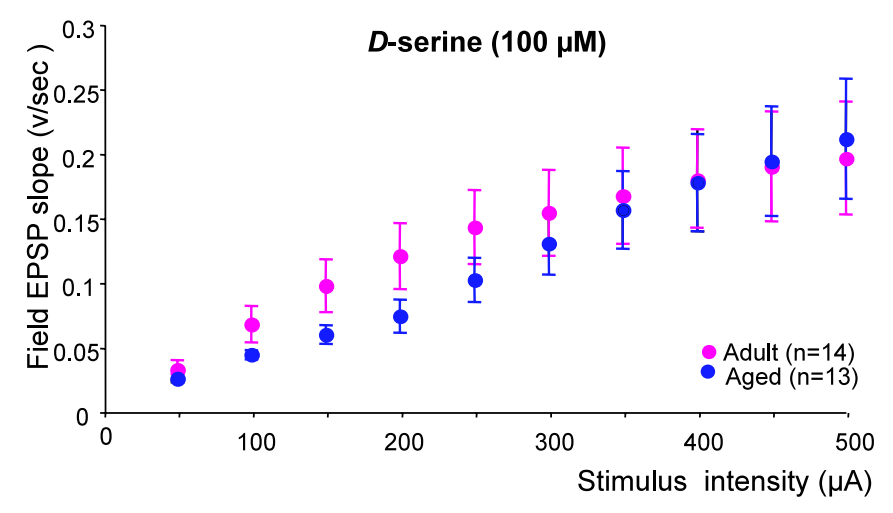

animals at multiple stimulus intensities (Figure 2B) indicated that the amplitude of these NMDA-R synaptic potentials was significantly reduced in aged rats (interaction of strain $\times$ intensity, $p=0.01)$.

Because NMDA-R synaptic potentials were also antagonized by $\mathrm{L} 689.560(10 \mu \mathrm{M})$, the specific blocker of the glycine modulatory site, we wondered whether changes affecting this binding site could underlie the age-related decrease in NMDA-R activation. We therefore checked the responsiveness of isolated NMDA-Rmediated synaptic potentials to an exogenous application of the specific agonist D-serine. As illustrated in Figure 2C, the amino acid dose-dependently enhanced these synaptic responses, but its potency was significantly higher in slices from aged rats than in those from young adults, regardless of the concentration of the co-agonist. Consequently, deficits in NMDA-R synaptic potentials were prevented in slices from aged animals supplied with D-serine (see Figure 2D). In contrast, L-serine (100 $\mu \mathrm{M})$, the precursor of $\mathrm{D}$-serine, did not significantly alter isolated NMDA-R synaptic potentials either in slices from adults $(n=10)$ or from old rats $(n=9)$. increasing stimulus intensities, recorded in control aCSF in adult and aged rats. (C) Bar graph of the mean increase in NMDA-R-mediated fEPSP slope ( \pm SEM) as a function of D-serine concentration in adult and aged rats $(\# p<0.05$ and $\# \# p<0.01$, unpaired $t$-test). Sample sizes are indicated in parentheses above the bars. (D) Plot of the mean NMDA-R-mediated fEPSP slope against increasing stimulus intensities, recorded in D-serine-supplemented aCSF in adult and aged rats.

\section{EFFECTS OF D-SERINE ON AGE-RELATED DEFICITS IN SYNAPTIC PLASTICITY}

Since isolated NMDA-R potentials were rescued from age-related alterations by boosting the activation of the glycine modulatory site, we asked whether deficits in the expression of synaptic plasticity in aged rats could also be reversed by the same procedure.

In slices from adults $(n=12)$, D-serine did not affect the magnitude of HFS-induced LTP, whereas it significantly increased the amplitude of potentiation in slices $(n=10)$ from old animals $(p<0.05$, Figure 3A, left). Under these conditions, in which the agonist saturated the glycine binding sites of the NMDA-R, HFS-induced LTP was higher in aged rats $(77.8 \pm 13.9 \%)$ than in younger ones $(55 \pm 11.6 \%)$ (Figure 3A, right), although this difference was not statistically relevant.

The effects of exogenous D-serine on depotentiation were then investigated. When the NMDA-R co-agonist was present in the aCSF during LFS delivery, the magnitude of depotentiation in slices from aged rats $(n=9)$ was significantly enhanced $(p<0.05)$, whereas no effect was seen in slices from adult rats $(n=6)$ (Figure 3B, left). Under these conditions, the age-related alteration of depotentiation was therefore prevented by $\mathrm{D}$-serine (Figure 3B, right). 
A
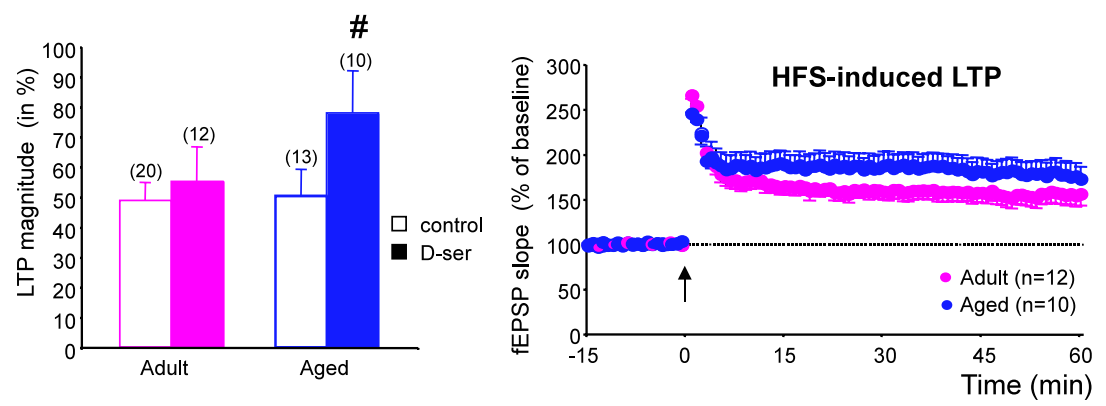

B
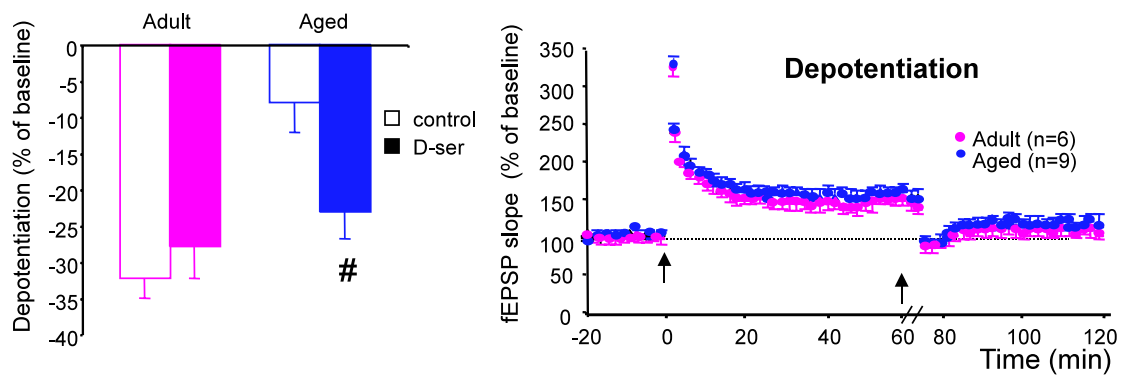

C
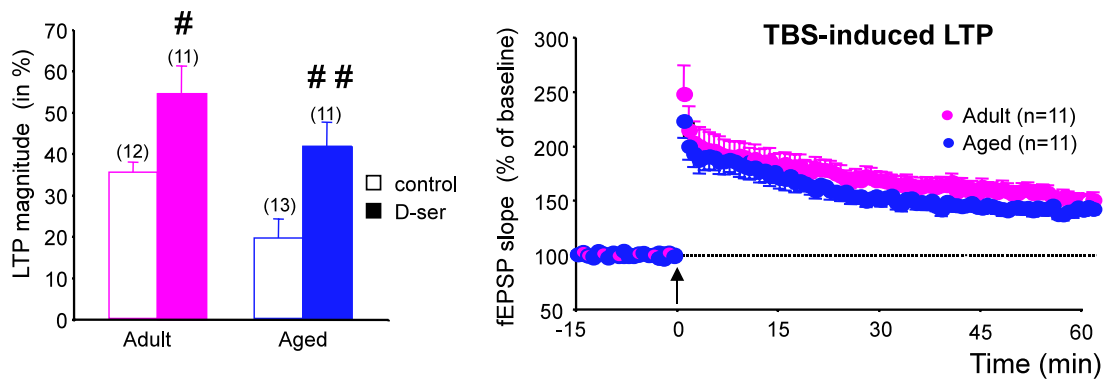

FIGURE 3 | D-serine alleviates the age-related deficit in synaptic plasticity. (A, left) Effects of D-serine $(100 \mu \mathrm{M})$ on the magnitude of HFS-induced LTP calculated for the last $15 \mathrm{~min}$ of recording. (A, right) Time-course of LTP induced

in adult and aged rats in the presence of the NMDA-R co-agonist. (B, C) Results obtained with TBS and depotentiation protocols respectively ( $\# p<0.05$, $\#$ \# $<0.01$, unpaired $t$-test).

Regarding the effects of by D-serine on TBS-induced LTP, the magnitude averaged over the last $15 \mathrm{~min}$ of recording was significantly increased in slices from both young adult $(n=11)$ and aged $(n=11)$ animals, but the increase was greater in the latter group (Figure 3A, left). Consequently, the age-related deficit in TBSinduced LTP was alleviated by the exogenous application of the NMDA-R co-agonist (Figure 3C, right).

\section{D-SERINE-DEPENDENT METABOLIC PATHWAYS IN AGING}

The impaired activation of the NMDA-R glycine modulatory site by endogenous $\mathrm{D}$-serine during aging may be due to changes in receptor affinity and/or the availability of the co-agonist in aged hippocampal tissues.

D-serine binding sites were abundantly present in the stratum radiatum and stratum oriens of the CA1 hippocampal region as well as in the dentate gyrus of both adult $(n=3)$ and aged $(n=3)$ animals, as revealed by the potent radioligand $\left[{ }^{3} \mathrm{H}\right] \mathrm{L} 689.560$. This ligand was dose-dependently displaced by unlabeled D-serine (from $3 \mathrm{nM}$ to $300 \mu \mathrm{M}$ ) to a similar extent in the two groups of animals and in all hippocampal subregions (Figures $4 \mathrm{~A}-\mathrm{C}$ ), indicating that the affinity of the NMDA-R glycine binding site for D-serine was not altered by age.

To determine whether aging alters the availability of the endogenous ligand, two different methods were applied. In the first, the levels of endogenous D-serine were determined by a specific chemiluminescent assay based on the D-amino acid oxidase/horseradish peroxidase/luminal system (Wolosker et al., 1999). With this method, we found that levels of the amino acid were significantly decreased in hippocampal tissues of old rats $(n=7)$ when compared with adults $(n=9)$ (Figure $4 \mathrm{D}$, left). In parallel, the amounts of D-serine as well as those of its precursor $\mathrm{L}$-serine were determined in a different pool of animals using conventional HPLC (Figure 4D, right). This experiment confirmed that hippocampal tissues derived from old rats $(n=7)$ had reduced levels of $\mathrm{D}$-serine whereas the 

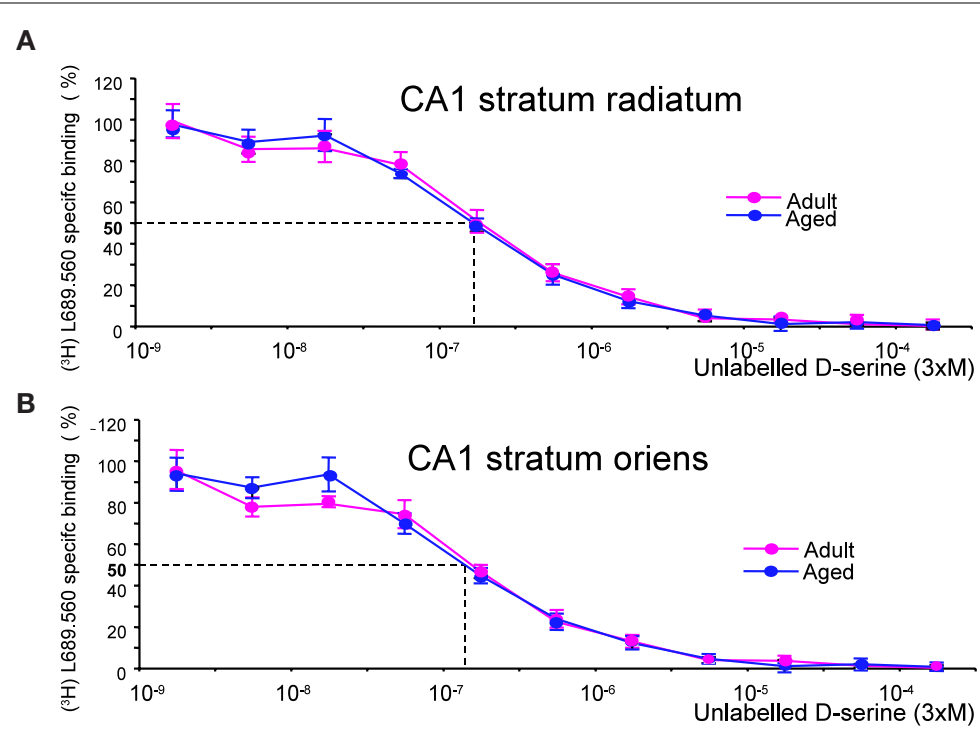

C

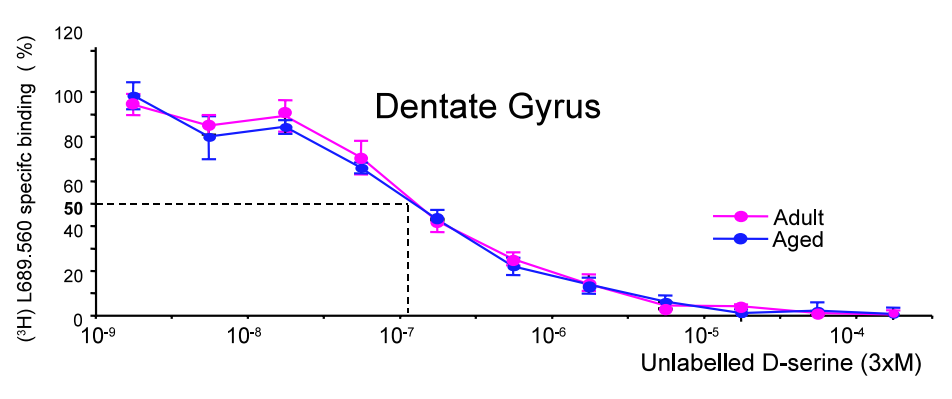

D
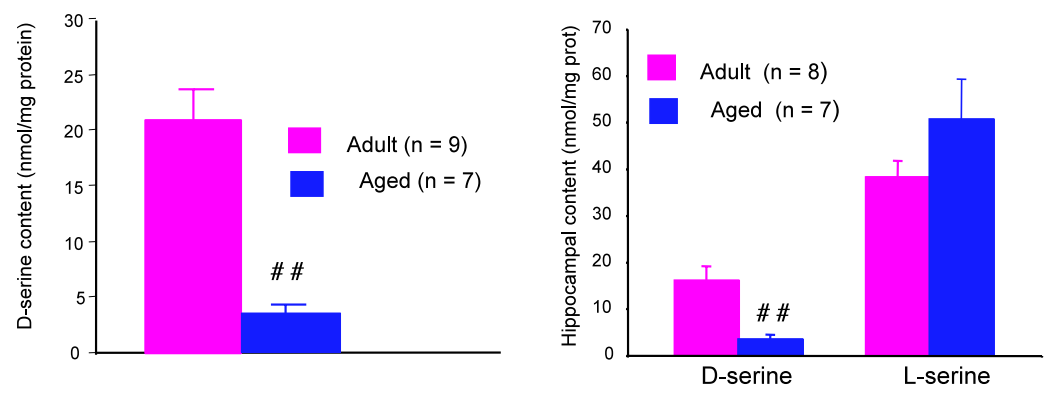

FIGURE 4 | Aging does not alter the affinity of $D$-serine binding sites but decreases $\mathrm{D}$-serine availability. Representative mean displacement curves of specific $\left[{ }^{3} \mathrm{H}\right] \mathrm{L} 689.560$ binding by D-serine in the stratum radiatum of the CA1 (A), the stratum oriens of the CA1 (B) and the dentate gyrus (C) respectively of adult and aged rats. (D, left). Bar graph of mean D-serine levels ( \pm SEM) determined by the chemiluminescent assay in adult and aged rats. (D, right) Bar graph of mean D-serine and L-serine levels ( \pm SEM) determined by HPLC in adult and aged rats (\#\#p<0.01, unpaired $t$-test). amount of L-serine tended to be higher (Figure 4D, right). As a consequence, the $\mathrm{D} / \mathrm{L}$-serine ratio was significantly lowered from 0.42 in young adult rats to 0.06 in old animals $(p<0.001)$.

This age-related decrease in $\mathrm{D} / \mathrm{L}$-serine ratio suggests that $\mathrm{D}$ serine metabolism is impaired. We therefore checked for the expression of serine racemase (SR) and D-amino-acid oxidase (DAAO), the enzymes synthesizing and degrading $\mathrm{D}$-serine respectively. In Western blots (Figure 5A), we detected a single band of 37$\mathrm{kDa}$ corresponding to the predicted molecular mass of SR. Semiquantitative analysis of samples from five young adult and five aged rats showed a significant age-related decrease in enzyme expression $(-42 \%, p<0.01)$ once the amount of protein loaded was normalized to $\alpha$-tubulin (Figure 5B). In contrast, the expression of DAAO, identified as a $39-\mathrm{kDa}$ band, (Figure 5A) was not affected in aged animals (Figure 5B).

Similar results were obtained for mRNA levels. Indeed, quantitative PCR showed that mRNA levels for SR were significantly decreased in the hippocampus of aged rats $(p<0.01)$, whereas those for DAAO were not modified (Figure 5C). It is worth noting that the expression of the glutamate metabolizing enzyme glutamine synthetase is not affected, indicating that the glutamine/glutamate cycle is not altered by aging. 
A

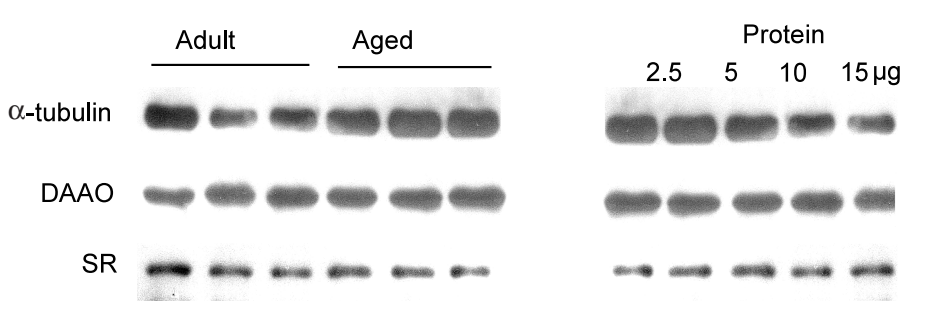

B
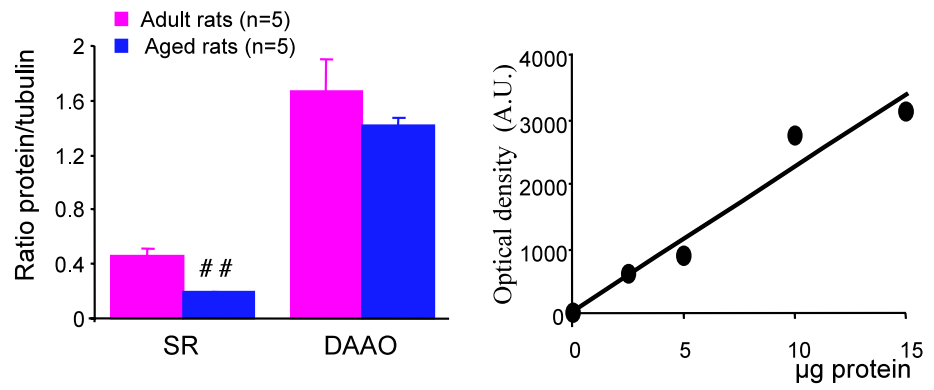

C

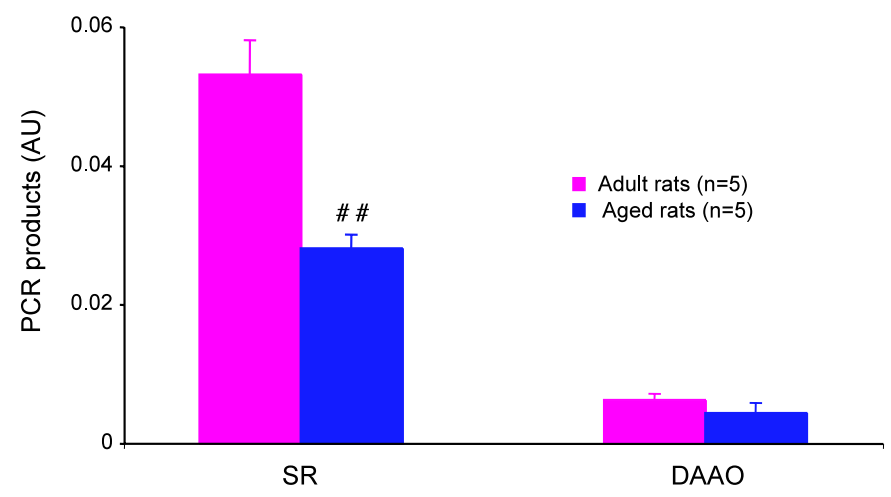

FIGURE 5 | Serine racemase expression is reduced in aged rats. (A, left) Immunoblots for $\alpha$-tubulin (upper band), DAAO (middle band) and serine racemase (lower band) in adult and aged rats. $10 \mu \mathrm{g}$ of protein were loaded per lane. (B, right) Immunoblots obtained with different amounts of protein loaded (2.5-15 $\mathrm{mg} / \mathrm{lane}$ ) in order to evaluate relative optical density variations. (B, left)
Quantitative analysis of immunoreactivity for serine racemase and DAAO in adult and aged rats, normalized to $\alpha$-tubulin. (B, right) Graph illustrating the linear relationship between optical density and the amount of protein loaded. (C) Bar graphs of mRNA levels of serine racemase and DAAO normalized to GFAP transcripts in adult and aged rats (\#\#p<0.01, unpaired $t$-test). AU, arbitrary unit.

\section{DISCUSSION}

In the last century, the mortality of the world population has been substantially delayed by improvements in hygiene and nutrition and by better treatment for illnesses. However, this increase in life expectancy is unfortunately associated with deficits in learning and memory (cognitive) or in motivation (emotional) (Grady and Craik, 2000; Craik and Bialystok, 2006; Luo and Craik, 2008). Over the past few decades, extensive behavioral experiments in animal models of aging, mainly conducted in aged rodents of different strains and species, have clearly shown how efficient learning and memory in young individuals is slowed down with age, while forgetfulness is accelerated (Winocur and Moscovitch, 1990; Gallagher and Rapp, 1997; Miyamoto, 1997; Houston et al., 1999; Norris and Foster, 1999; Clayton et al., 2002b; Sykova et al., 2002; Gruart et al., 2008). In accordance with these studies, we have shown in our investigation that spatial learning is altered in aged Sprague-Dawley rats, independent of sensory and/or motor dysfunctions. Identifying the functional changes in the brain that underlie cognitive aging is now of particular importance in order to improve quality of life in the elderly.

In the present report, we show that age-related deficits in spatial memory are correlated with changes in the ability of the aging brain to drive synaptic plasticity in neuronal networks of the hippocampus (see Junjaud et al., 2006; Mothet et al., 2006; Billard and Rouaud, 2007). When moderate synaptic activation is concerned, such as the activation evoked by TBS paradigms, the expression of LTP is impaired in aged animals (Moore et al., 1993; Tombaugh et al., 2002). We show that this form of LTP is blocked by the specific NMDA-R antagonist D-APV in both young adult and aged animals. Its impairment in the aging hippocampus is therefore likely to reflect a weaker activation of these subtypes of glutamatergic receptors. In contrast, age-related deficits in LTP are overridden by the 
stronger synaptic activation induced by HFS protocols, indicating that additional mechanisms have come into play to compensate for the impaired NMDA-R activation. Indeed, synaptic plasticity is completely blocked in the hippocampus of aged rats only if HFS is delivered in the presence of D-APV and of the antagonist nifedipine, indicating that VGCCs also contribute to HFS-induced LTP in aged animals, as previously suggested (Shankar et al., 1998). Whatever the mechanisms that compensate for impaired NMDA-R activation, behavioral experiments reveal that they are not helpful in maintaining memory capacity in aged subjects at young adult levels. It is worth noting that VGCC activation is not related to memory acquisition, but only to the retention of information (Borroni et al., 2000) and that the excessive activation of the L-subtype of VGCCs may be detrimental to memory formation (Liu et al., 2003). Furthermore, we have shown that LTP is rapidly depotentiated in adult but not in aged animals, using an LFS protocol (Kamal et al., 1998). Since LTP saturation disrupts memory formation in young rats (Moser and Moser, 1999), a reduced capacity of hippocampal networks to be reset from potentiated levels may also constitute a synaptic mechanism contributing to cognitive aging. On the other hand, it has been reported that HFS-induced LTP is impaired in aged mice in vivo (Gruart et al., 2008), indicating that compensatory mechanisms involving VGCCs do not occur in this species. Alternatively, this discrepancy with our own results could be due to differences in experimental protocols (in vivo vs. in vitro, age of the animals, number of conditioning trains of stimuli).

As discussed above, age-related changes in synaptic plasticity are likely to reflect a shift in calcium sources, with a weaker role for NMDA-R and an increased contribution of VGCCs and intracellular stores with different kinetic properties, at least in the rat hippocampus (Kumar and Foster, 2005; Gant et al., 2006; Foster, 2007; Thibault et al., 2007). Our investigations confirm the agerelated impairment in NMDA-R activation, as demonstrated by the decrease in the magnitude of isolated NMDA-R-dependent synaptic potentials in old animals (see also Barnes et al., 1997; Potier et al., 2000). Considering that only postsynaptic determinants are concerned (Burke and Barnes, 2006), it could be expected that a decrease in receptor number underlies this impairment. Accordingly, Clayton et al. (2002b) have reported that age-associated changes in LTP expression can be mimicked by reducing the density of NR2B subunits. Several studies have also shown that the number of NMDA receptors is decreased in the hippocampus of aged rats and mice, and that this decrease is correlated with memory impairments. However, this has not been seen in other studies and many investigations instead support the idea that NMDA-R density is unchanged or even increased during aging (see Billard et al., 1997 for a review). In addition, it has recently been shown in aged Lou/ $\mathrm{C} /$ Jall rats that NMDA-R number is significantly reduced without changes in memory abilities or synaptic plasticity (Kollen et al., 2010). Finally, the present study shows that the magnitude of isolated NMDA-R-mediated potentials is not different in young adult and aged rats when all NMDA-Rs are recruited with saturating concentrations of the co-agonist $\mathrm{D}$-serine. Taken together, these data indicate that an age-related decrease in NMDA-R number is not an essential mechanism in the weaker response of these receptors in aged animals, but rather the changes in their functional and/or pharmacological properties that are concerned.
$N$-Methyl-D-aspartate receptors activation relies on a voltagedependent blockade by magnesium (Nowak et al., 1984) that is not affected in aged animals (Potier et al., 2000). It also needs the binding of a co-agonist at the strychnine-insensitive glycine modulatory site (Johnson and Ascher, 1987). In the last few years, the amino acid D-serine has been proposed as the main endogenous co-agonist of NMDA-R in the hippocampus, since its function, as revealed by biochemical and electrophysiological methods, are weakened by the selective degradation of $\mathrm{D}$-serine by the degrading enzyme DAAO (Mothet et al., 2000; Yang et al., 2003). Our study shows that exogenous D-serine enhances isolated NMDA-R-mediated synaptic responses in both young adult (see also Watanabe et al., 1992; Martina et al., 2003; Krasteniakov et al., 2005) and aged rats but that the potency of the co-agonist is higher in the latter group. In addition, we have found that $\mathrm{D}$-serine is able to reverse the agerelated deficits in NMDA-R-mediated synaptic potentials and synaptic plasticity, including TBS-induced LTP and depotentiation, as has been previously reported in senescence-accelerated (SAMP8) mice (Yang et al., 2005). These results therefore indicate that the reduced activation of NMDA-R glycine binding sites by endogenous $\mathrm{D}$-serine is a potent mechanism underlying the age-related deficits in synaptic plasticity.

The increased efficacy of $\mathrm{D}$-serine supplementation with age may reflect changes in the degree of receptor saturation, determined by the specific affinity of the glycine modulatory site and/or changes in endogenous $\mathrm{D}$-serine levels. Our binding studies have indicated that receptor affinity for $\mathrm{D}$-serine remains unaffected in aged Sprague-Dawley rats, as reported in other strains of rats and in mice (Miyoshi et al., 1990; Nagata et al., 1998). In contrast, we provide evidence to show that endogenous levels of $\mathrm{D}$-serine are dramatically reduced with aging. This result differs from previous studies showing no changes in D-serine levels in aged Wistar rats (Hashimoto et al., 1993) and SAMP8 mice (Nagata et al., 1998). A possible explanation for this discrepancy lies in differences between species or strains. Nevertheless, we have recently found that D-serine levels are also decreased in the hippocampus of aged Wistar rats (Turpin et al., 2009). An alternative possibility is that age-related changes in D-serine levels occur in restricted areas of the brain, since we used isolated hippocampi in our experiments whereas the study of Hashimoto et al. (1993) was performed with whole brain extracts.

The fact that $\mathrm{D}$-serine levels are decreased while those of its precursor L-serine are simultaneously increased strongly argues for changes in the D-serine biosynthetic pathway during aging. Accordingly, we found that the expression of the synthesizing enzyme serine racemase is weakened in old rats, both at the mRNA and protein levels, whereas DAAO is not affected. It remains to be determined whether the activity of serine racemase is also altered. Other mechanisms amplifying the age-related decrease in the synaptic availability of $\mathrm{D}$-serine, such as changes in its diffusion rate in the extracellular space (Sykova et al., 1998, 2002) and/or an increased reuptake by membrane transporters in both neuronal and glial cells (see Billard, 2008 for a review), remain to be investigated.

The ability of $\mathrm{D}$-serine to prevent age-related deficits in synaptic plasticity makes this amino acid an attractive tool for the reduction of memory dysfunction in the aged. It is worth noting that 
defects in spatial memory in aged rats (Aura and Riekkinen, 2000) and the disruption of the hippocampus-dependent associative eyeblink conditioning in old rabbits (Thompson and Disterhoft, 1997) are reduced by the partial agonist $\mathrm{D}$-cycloserine, which also alleviates the age-related deficit in NMDA-R-mediated synaptic plasticity by acting on the glycine-binding site (Billard and Rouaud, 2007). Unfortunately, the possibility of the long-term treatment of cognitive defects with large doses of $\mathrm{D}$-cycloserine or with $\mathrm{D}$-serine itself has been discarded, because the former leads to side-effects in the central nervous system while the latter induces the DAAO-dependent necrosis of the terminal portions of the proximal renal tubules (Williams and Lock, 2004; Krug et al., 2007). Alternatively, the fact that serine racemase is selectively affected in aged tissues opens new perspectives in the search for relevant strategies to reduce the memory impairment associated with aging, as has been recently suggested for neurological disorders including schizophrenia and Alzheimer's disease (Labrie et al., 2009; Tsai and Lin, 2009, see Billard, 2008 for a review).

\section{SUPPLEMENTARY MATERIAL}

The Supplementary Material for this article can be found online at http://www.frontiersin.org/agingneuroscience/paper/10.3389/ neuro.24/001.2010/

\section{REFERENCES}

Aura, J., and Riekkinen, P., Jr. (2000). Pre-training blocks the improving effect of tetrahydroaminoacridine and D-cycloserine on spatial navigation performance in aged rats. Eur. J. Pharmacol. 390, 313-318.

Barnes, C. A. (2003). Long-term potentiation and the ageing brain. Philos. Trans. R. Soc. Lond., B, Biol. Sci. 358, 765-772.

Barnes, C. A., Rao, G., and Shen, J. (1997). Age-related decrease in the $\mathrm{N}$-methylD-aspartateR-mediated excitatory postsynaptic potential in hippocampal region CA1. Neurobiol. Aging 18, 445-452.

Billard, J. M. (2008). D-Serine signalling as a prominent determinant of neuronal-glial dialogue in the healthy and diseased brain. J. Cell. Mol. Med. 12, 1872-1884.

Billard, J. M., Jouvenceau, A., Lamour, Y., and Dutar, P. (1997). NMDA receptor activation in the aged rat: electrophysiological investigations in the CA1 area of the hippocampal slice ex vivo. Neurobiol. Aging 18, 535-542.

Billard, J. M., and Rouaud, E. (2007). Deficit of NMDA receptor activation in CA1 hippocampal area of aged rats is rescued by D-cycloserine. Eur. J. Neurosci. 25, 2260-2268.

Borroni, A. M., Fichtenholtz, H., Woodside, B. L., and Teyler, T.J. (2000). Role of voltage-dependent calcium channel long-term potentiation (LTP) and NMDA LTP in spatial memory. $J$. Neurosci. 20, 9272-9276.

Burke, S. N., and Barnes, C. A. (2006). Neural plasticity in the ageing brain. Nat. Rev. Neurosci. 7, 30-40.

Clayton, D. A., Grosshans, D. R., and Browning, M. D. (2002a). Aging and surface expression of hippocampal NMDA receptors. J. Biol. Chem. 277, 14367-14369.

Clayton, D.A., Mesches, M.H., Alvarez, E., Bickford, P. C., and Browning, M. D. (2002b). A hippocampal NR2B deficit can mimic age-related changes in longterm potentiation and spatial learning in the Fischer 344 rat. J. Neurosci. 22, 3628-3637.

Craik, F. I., and Bialystok, E. (2006). Cognition through the lifespan: mechanisms of change. Trends Cogn. Sci. (Regul. Ed.) 10, 131-138.

Foster, T. C. (1999). Involvement of hippocampal synaptic plasticity in agerelated memory decline. Brain Res. Brain Res. Rev. 30, 236-249.

Foster, T.C. (2007). Calcium homeostasis and modulation of synaptic plasticity in the aged brain. Aging Cell 6, 319-325.

Foster, T. C., and Norris, C. M. (1997). Age-associated changes in $\mathrm{Ca} 2+-$ dependent processes: relation to hippocampal synaptic plasticity. Hippocampus 7, 602-612.

Gallagher, M., and Rapp, P. R. (1997). The use of animal models to study the effects of aging on cognition. Annu. Rev. Psychol. 48, 339-370.

Gant, J. C., Sama, M. M., Landfield, P. W., and Thibault, O. (2006). Early and simultaneous emergence of multiple hippocampal biomarkers of aging is mediated by $\mathrm{Ca} 2+$-induced $\mathrm{Ca} 2+$ release. J. Neurosci. 26, 3482-3490.

Grady, C. L., and Craik, F. I. (2000). Changes in memory processing with age. Curr. Opin. Neurobiol. 10, 224-231.

Gruart,A., Lopez-Ramos, J.C., Munoz, M. D., and Delgado-Garcia, J. M. (2008). Aged wild-type and APP, PS1, and APP + PS1 mice present similar deficits in associative learning and synaptic plasticity independent of amyloid load. Neurobiol. Dis. 30, 439-450.

Hashimoto, A., Nishikawa, T., Oka, T., and Takahashi, K. (1993). Endogenous D-serine in rat brain: $N$-methyl-Daspartate receptor-related distribution and aging. J. Neurochem. 60, 783-786.

Houston, F. P., Stevenson, G. D., McNaughton, B. L., and Barnes, C. A. (1999). Effects of age on the generalization and incubation of memory in the F344 rat. Learn. Mem. 6, 111-119.

Izquierdo, I., and Medina, J. H. (1995). Correlation between the pharmacology of long-term potentiation and the pharmacology of memory. Neurobiol. Learn. Mem. 63, 19-32.

Johnson, J. W., and Ascher, P. (1987). Glycine potentiates the NMDA response in cultured mouse brain neurons. Nature 325, 529-531.

Johnson, J. W., and Ascher, P. (1990). Voltage-dependent block by intracellular $\mathrm{Mg} 2+$ of $\mathrm{N}$-methyl-D-aspartate-activated channels. Biophys. J. 57, 1085-1090.

Junjaud, G., Rouaud, E., Turpin, F., Mothet, J. P., and Billard, J. M. (2006). Age-related effects of the neuromodulator D-serine on neurotransmission and synaptic potentiation in the CA1 hippocampal area of the rat. $J$. Neurochem. 98, 1159-1166.

Kamal, A., Biessels, G. J., Gispen, W. H., and Urban, I. J. (1998). Increasing age reduces expression of long-term depression and dynamic range of transmission plasticity in CA1 field of the rat hippocampus. Neuroscience 83, 707-715.

Kim, S. J., and Linden, D. J. (2007). Ubiquitous plasticity and memory storage. Neuron 56, 582-592.

Kollen, M., Stephan, A., Faivre-Bauman, A., Loudes, C., Sinet, P. M., Alliot, J., Billard, J. M., Epelbaum, J., Dutar, P., Jouvenceau, A. (2010). Preserved memory capacities in aged Lou/C/Jall rats. Neurobiol. Aging. 31, 129-142.

Krasteniakov, N. V., Martina, M., and Bergeron, R. (2005). Role of the glycine site of the $N$-methyl-D-aspartate receptor in synaptic plasticity induced by pairing. Eur. J. Neurosci. 21, 2782-2792.

Krug,A.W., Volker, K., Dantzler, W.H., and Silbernagl, S. (2007). Why is D-serine nephrotoxicandalpha-aminoisobutyric acid protective? Am. J. Physiol. Renal Physiol. 293, F382-F390.

Kumar, A., and Foster, T. C. (2005). Intracellular calcium stores contribute to increased susceptibility to LTD induction during aging. Brain Res. 1031, 125-128.

Labrie, V., Fukumura, R., Rastogi, A., Fick, L. J., Wang, W., Boutros, P.C., Kennedy,
J.L., Semeralul, M.O., Lee, F.H., Baker, G. B., Belsham, D. D., Barger, S. W., Gondo, Y., Wong, A. H., and Roder, J. C. (2009). Serine racemase is associated with schizophrenia susceptibility in humans and in a mouse model. Hum. Mol. Genet. 18, 3227-3243.

Landfield, P. W. (1988). Hippocampal neurobiological mechanisms of age-related memory dysfunction. Neurobiol. Aging 9, 571-579.

Liu, R., Liu, I. Y., Bi, X., Thompson, R. F., Doctrow, S. R., Malfroy, B., and Baudry, M. (2003). Reversal of age-related learning deficits and brain oxidative stress in mice with superoxide dismutase/catalase mimetics. Proc. Natl. Acad. Sci. U.S.A. 100, 8526-8531.

Luo, L., and Craik, F. I. (2008). Aging and memory: a cognitive approach. Can. J. Psychiatry 53, 346-353.

Lynch, M. A. (2004). Long-term potentiation and memory. Physiol. Rev. 84, 87-136.

Martina, M., Krasteniakov, N. V., and Bergeron, R. (2003). D-Serine differently modulates NMDA receptor function in rat CAl hippocampal pyramidal cells and interneurons. J. Physiol. (Lond.) 548, 411-423.

Miyamoto, M. (1997). Characteristics of age-related behavioral changes in senescence-accelerated mouse SAMP8 and SAMP10. Exp. Gerontol. 32, 139-148.

Miyoshi, R., Kito, S., Doudou, N., and Nomoto, T. (1990). Age-related changes of strychnine-insensitive glycine receptors in rat brain as studied by in vitro autoradiography. Synapse 6, 338-343.

Moore, C. I., Browning, M. D., and Rose, G. M. (1993). Hippocampal plasticity induced by primed burst, but not long-term potentiation, stimulation is impaired in area $\mathrm{CAl}$ of aged Fischer 344 rats. Hippocampus 3, 57-66.

Morris, R. G., Garrud, P., Rawlins, J. N., and O'Keefe, J. (1982). Place navigation impaired in rats with hippocampal lesions. Nature 297, 681-683.

Moser, E. I., and Moser, M. B. (1999). Is learning blocked by saturation of 
synaptic weights in the hippocampus? Neurosci. Biobehav. Rev. 23, 661-672.

Mothet, J. P., Parent, A. T., Wolosker, H., Brady, R. O., Jr., Linden, D. J., Ferris, C. D., Rogawski, M. A., and Snyder, S. H. (2000). D-Serine is an endogenous ligand for the glycine site of the $N$ methyl-D-aspartate receptor. Proc. Natl. Acad. Sci. U.S.A. 97, 4926-4931.

Mothet, J. P., Rouaud, E., Sinet, P. M., Potier, B., Jouvenceau, A., Dutar, P., Videau, C., Epelbaum, J., and Billard, J.M. (2006). A critical role for the glialderived neuromodulator $\mathrm{D}$-serine in the age-related deficits of cellular mechanisms of learning and memory. Aging Cell 5, 267-274.

Nagata, Y., Uehara, T., Kitamura, Y., Nomura, Y., and Horiike, K. (1998). $\mathrm{D}$-Serine content and $\mathrm{D}-[3 \mathrm{H}]$ serine binding in the brain regions of the senescence-accelerated mouse. Mech. Ageing Dev. 104, 115-124.

Norris, C. M., and Foster, T. C. (1999). MK-801 improves retention in aged rats: implications for altered neural plasticity in age-related memory deficits. Neurobiol. Learn. Mem. 71, 194-206.

Nowak, L., Bregestovski, P., Ascher, P., Herbet, A., and Prochiantz, A. (1984). Magnesium gates glutamate-activated channels in mouse central neurones. Nature 307, 462-465.

Potier, B., Poindessous-Jazat, F., Dutar, P., and Billard, J. M. (2000). NMDA receptor activation in the aged rat hippocampus. Exp. Gerontol. 35, 1185-1199.

Puyal, J., Devau, G., Venteo, S., Sans, N., and Raymond, J. (2002).
Calcium-binding proteins map the postnatal development of rat vestibular nuclei and their vestibular and cerebellar projections. J. Comp. Neurol. 451, 374-391.

Rosenzweig, E. S., and Barnes, C.A. (2003). Impact of aging on hippocampal function: plasticity, network dynamics, and cognition. Prog. Neurobiol. 69, 143-179.

Shankar, S., Teyler, T. J., and Robbins, N. (1998).Aging differentially alters forms of long-term potentiation in rat hippocampal area CA1. J. Neurophysiol. 79, 334-341.

Sykova, E., Mazel, T., Hasenohrl, R. U., Harvey, A. R., Simonova, Z., Mulders, W. H., and Huston, J. P. (2002). Learning deficits in aged rats related to decrease in extracellular volume and loss of diffusion anisotropy in hippocampus. Hippocampus 12, 269-279.

Sykova, E., Mazel, T., and Simonova, Z. (1998). Diffusion constraints and neuron-glia interaction during aging. Exp. Gerontol. 33, 837-851.

Thibault, O., Gant, J. C., and Landfield, P. W. (2007). Expansion of the calcium hypothesis of brain aging and Alzheimer's disease: minding the store. Aging Cell 6, 307-317.

Thompson, L. T., and Disterhoft, J. F. (1997). Age- and dose-dependent facilitation of associative eyeblink conditioning by $\mathrm{D}$-cycloserine in rabbits. Behav. Neurosci. 111, 1303-1312.

Tombaugh, G. C., Rowe, W. B., Chow, A. R., Michael, T. H., and Rose, G. M. (2002). Theta-frequency synaptic potentiation in CA1 in vitro distinguishes cognitively impaired from unimpaired aged Fischer 344 rats. J. Neurosci. 22, 9932-9940.

Tsai, G. E., and Lin, P.Y. (2009). Strategies to enhance $N$-methyl-D-aspartate receptor-mediated neurotransmission in schizophrenia, a critical review and meta-analysis. Curr. Pharm. Des. [Epub ahead of print], PMID: 19909229.

Turpin, F. R., Potier, B., Dulong, J. R., Sinet, P. M., Alliot, J., Oliet, S. H., Dutar, P., Epelbaum, J., Mothet, J. P., and Billard, J. M. (2009). Reduced serine racemase expression contributes to age-related deficits in hippocampal cognitive function. Neurobiol. Aging. doi: 10.1016/ j.neurobiolaging.2009.09.001.

Wang,J.H., Ko, G.Y., and Kelly, P.T. (1997). Cellular and molecular bases of memory: synaptic and neuronal plasticity. $J$. Clin. Neurophysiol. 14, 264-293.

Watanabe, Y., Saito, H., and Abe, K. (1992). Effects of glycine and structurally related amino acids on generation of long-term potentiation in rat hippocampal slices. Eur. J. Pharmacol. 223, 179-184.

Williams, R. E., and Lock, E. A. (2004). D-Serine-induced nephrotoxicity: possible interaction with tyrosine metabolism. Toxicology 201, 231-238.

Winocur, G., and Moscovitch, M. (1990). Hippocampal and prefrontal cortex contributions to learning and memory: analysis of lesion and aging effects on maze learning in rats. Behav. Neurosci. 104, 544-551.

Wolosker, H., Blackshaw, S., and Snyder, S. H. (1999). Serine racemase: a glial enzyme synthesizing $\mathrm{D}$-serine to regulate glutamate- $N$-methyl-D-aspartate neurotransmission. Proc. Natl. Acad. Sci. U.S.A. 96, 13409-13414.
Yang, S., Qiao, H., Wen, L., Zhou, W., and Zhang, Y. (2005). D-Serine enhances impaired long-term potentiation in CA1 subfield of hippocampal slices from aged senescence-accelerated mouse prone/8. Neurosci Lett. 379, 7-12.

Yang, Y., Ge, W., Chen, Y., Zhang, Z., Shen, W., Wu, C., Poo, M., and Duan, S. (2003). Contribution of astrocytes to hippocampal long-term potentiation through release of D-serine. Proc. Natl. Acad. Sci. U.S.A. 100, 15194-15199.

Conflict of Interest Statement: The authors declare that the research was conducted in the absence of any commercial or financial relationships that could be construed as a potential conflict of interest.

Received: 10 November 2009; paper pending published: 17 November 2009; accepted: 07 January 2010; published online: 05 February 2010.

Citation: Potier B, Turpin FR, Sinet P-M, Rouaud E, Mothet J-P, Videau C, Epelbaum J, Dutar P and Billard J-M (2010) Contribution of the $\mathrm{D}$-Serine-dependent pathway to the cellular mechanisms underlying cognitive aging. Front. Ag. Neurosci. 2:1. doi: 10.3389/neuro.24.001.2010 Copyright $\odot 2010$ Potier, Turpin, Sinet, Rouaud, Mothet, Videau, Epelbaum, Dutar and Billard. This is an open-access article subject to an exclusive license agreement between the authors and the Frontiers Research Foundation, which permits unrestricted use, distribution, and reproduction in any medium, provided the original authors and source are credited. 